\title{
Design and Synthesis of Enantiopure Tetrakis(pentafluoro- phenyl) Borate Analogues for Asymmetric Counteranion Directed Catalysis
}

\author{
Chandra Kanta De, Raja Mitra, and Benjamin List*
}

Max-Planck-Institut für Kohlenforschung

Kaiser-Wilhelm-Platz 1

45470 Mülheim an der Ruhr, Germany

list@mpi-muelheim.mpg.de
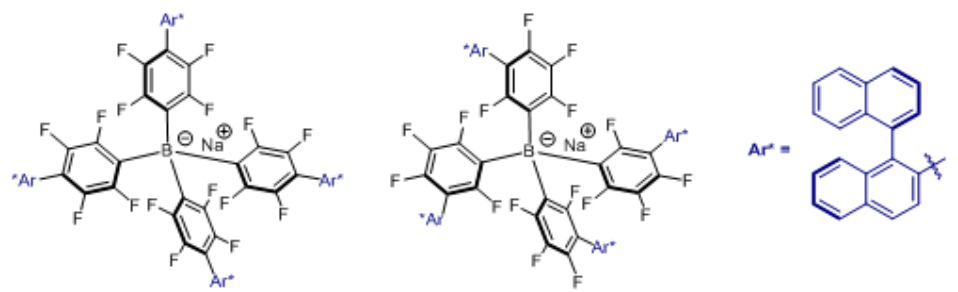

\begin{abstract}
The design and five step synthesis of chiral tetrakis(pentafluoro-phenyl) borate analogues from commercially available enantiopure BINOL is described. The chiral anions have been tested in a catalytic asymmetric Mukaiyama aldol reaction.
\end{abstract}

Key words: Asymmetric counteranion-directed catalysis (ACDC), weakly coordinating anion (WCA), chiral BArF, Mukaiyama aldol reaction

Asymmetric counteranion-directed catalysis $(A C D C)^{1}$ has recently been recognized as a broadly applicable approach to asymmetric synthesis. It refers to "the induction of enantioselectivity in a reaction proceeding through a cationic intermediate by means of ion pairing with a chiral, enantiomerically pure anion provided by the catalyst". ${ }^{1 f}$ Recently, intensive research on pairing catalytically-generated cationic intermediates, such as iminium ions, oxocarbenium ions, and cationic organometallic fragments, with enantiopure anions has led to several new asymmetric reactions. ${ }^{2,3}$ ACDC with silylium ion equivalents has emerged as a particularly powerful strategy for Lewis acid organocatalysis. As depicted in Scheme 1, the character of the Si- $X^{*}$ bond of the catalyst can be tuned by modifying the counteranion. To increase the Lewis acidity on silicon, the counteranion has to be less basic. We are interested in exploring ever more reactive silylium-ACDC catalysts and therefore in the design of weakly basic (or "weakly coordinating") chiral anions. ${ }^{3 c}$ Our studies have led to the advancement of the relatively mildly acidic chiral phosphoric acids to more confined IDP catalysts, $^{3 \mathrm{~d}}$ more acidic DSI catalysts, ${ }^{3 \mathrm{c}}$ much more acidic BALT catalysts, ${ }^{3 e}$ and recently to highly confined and highly acidic IDPi catalysts, ${ }^{3 f}$ which enable powerful silylium-ACDC processes. In the extreme scenario of a super strong silylium Lewis acid catalyst, the
Si-X* bond would be completely ionic. ${ }^{4 a}$ Toward achieving this, non-coordinating chiral anions are required. The fascinating question whether or not such anions will be capable of inducing asymmetry may appear contradictorily, but is certainly in need of an answer. Here we report the design and synthesis of chiral enantiopure tetrakis(pentafluorophenyl) borate $\left(\mathrm{B}\left(\mathrm{C}_{6} \mathrm{~F}_{5}\right)_{4}{ }^{-}\right)$analogues and their exploration in the Mukaiyama aldol reaction.

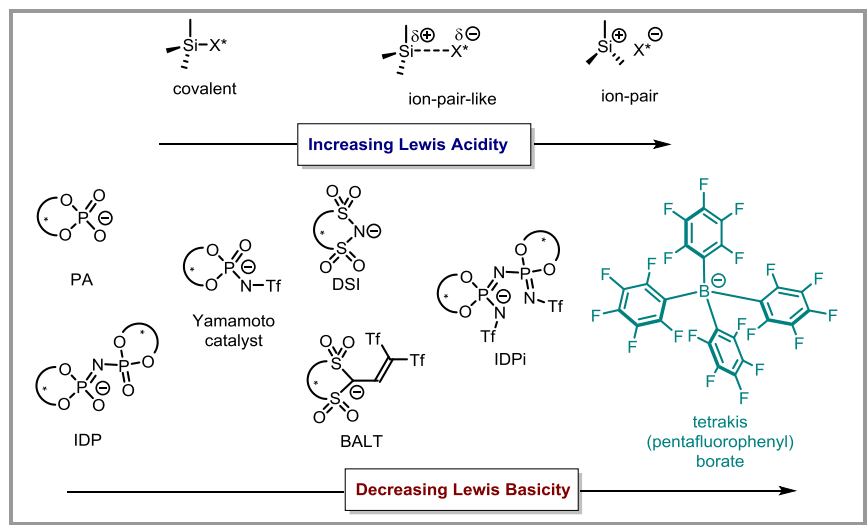

Scheme 1 Effect of the chiral counteranions on silylium Lewis acidity. $(\mathrm{Tf}=$ $\left.-\mathrm{SO}_{2} \mathrm{CF}_{3}\right)$

So-called non-coordinating or weakly coordinating anions (WCAs) are becoming increasingly relevant in fundamental and applied chemistry due to their versatile utilities. ${ }^{4,5}$ Examples of weakly coordinating anions include $\left[\mathrm{B}\left(\mathrm{C}_{6} \mathrm{~F}_{5}\right)_{4}\right]^{-},\left[\mathrm{Sb}\left(\mathrm{OTeF}_{5}\right)_{6}\right]^{-},\left[\mathrm{CB}_{11} \mathrm{Me}_{6} \mathrm{X}_{6}\right]^{-}$and $\left[\mathrm{Al}\left(\mathrm{OR}^{\mathrm{F}}\right)_{4}\right]^{-}$. To develop a weakly coordinating anion, its interaction with the cation has to be minimized, which can be achieved by delocalizing the negative charge over a large, non-nucleophilic area. While it remains challenging to design a WCA with essentially no interaction with its countercation, an anion is considered "non-coordinating" 
when its coordination towards the cation is weaker than that of surrounding solvent molecules.

We became interested in designing chiral tetrakis(pentafluorophenyl) borate $\left(\mathrm{B}_{(}\left(\mathrm{C}_{6} \mathrm{~F}_{5}\right)_{4}^{-}\right)$analogues. Toward this end, we decided to attach a chiral 1,1'binaphthalen-2-yl unit onto the perfluorinated aryl groups of the borate anion leading to salts $\mathbf{4 a}$ and $\mathbf{4 b}$ (Scheme 2).

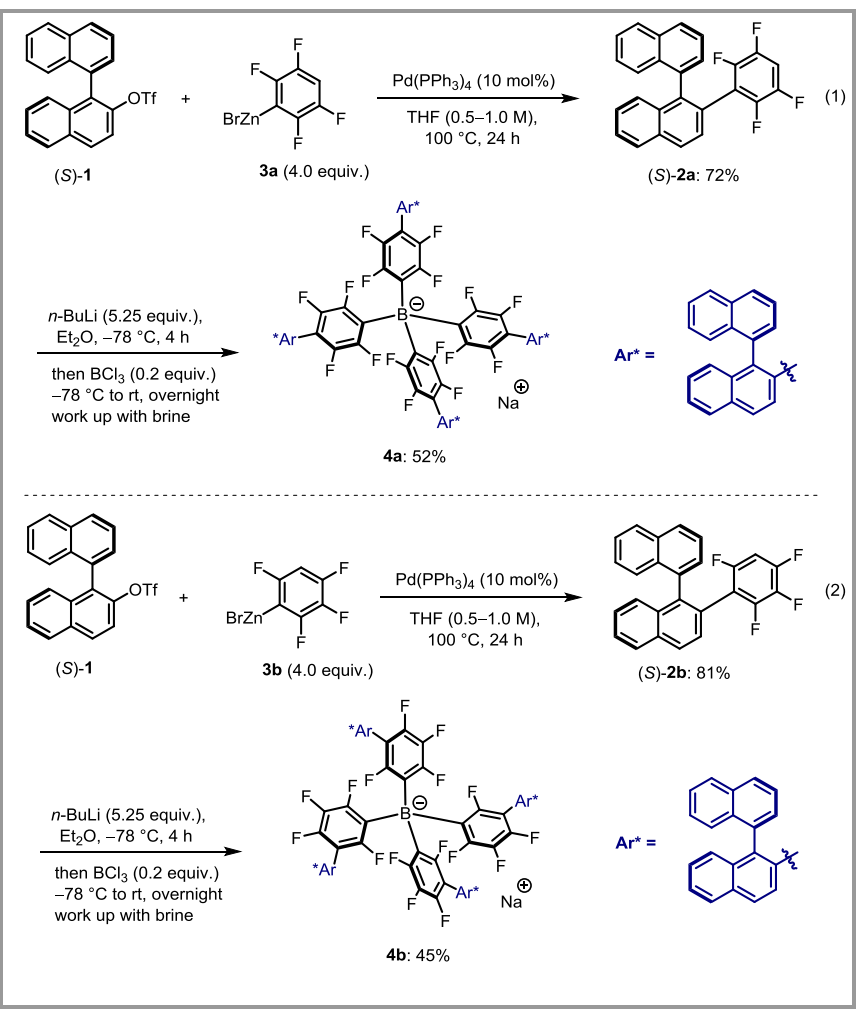

Scheme 2 Preparation 2-tetrafluorophenyl-1,1'-binaphthalene 1 and its application to synthesis of $\mathrm{BAr}^{\mathrm{F}} 4$

Our synthesis commenced with (S)-[1,1'-binaphthalen]-2-yl trifluoromethanesulfonate (1) which was prepared from commercially available $(R)$-BINOL in three steps on a gram-scale following a literature known procedure. ${ }^{6}$ Our initial efforts toward incorporating a tetrafluorophenyl unit onto binaphthyltriflate $(S)-\mathbf{1}$ via Suzuki coupling with the corresponding tetrafluorophenyl boronic acid yielded only trace amounts of product 2a. An alternative approach for the Suzuki coupling could be reversing the reacting partners, i.e. a reaction between [1,1'-binaphthalen]-2ylboronic acid and tetra-fluoro-bromobenzene. However, this would require an additional step to synthesize [1,1'binaphthalen]-2-ylboronic acid from binaphthyltriflate $(S)-1$ via Miyaura borylation.

Gratifyingly, we found that when binaphthyltriflate $(S)$-1 was reacted with 2,3,5,6-tetrafluorophenyl zinc bromide (3a) under Negishi cross-coupling conditions, (S)-2a was obtained in $72 \%$ yield (Scheme 2 , eq. 1 ). Under similar conditions, the reaction between (S)-1 and 2,3,4,6tetrafluoro-phenyl zinc bromide (3b) provided (S)-2b in $81 \%$ yield (Scheme 2, eq. 2). Next, we utilized these two (S)-2-tetrafluorophenyl-1,1'-binaphthalenes to synthesize enantiopure chiral borate sodium salts. Accordingly, a one pot protocol in which a $\mathrm{C}-\mathrm{H}$ lithiation was followed by reacting the resulting aryl lithium species with boron trichloride furnished sodium borate salts $\mathbf{4 a}$ and $\mathbf{4 b}$ in $52 \%$ and $45 \%$ isolated yield, respectively (Scheme 2 ).

Our next goal was to explore these enantiopure counteranions in enantioselective catalysis. Toward this end, the Lewis acid catalyzed Mukaiyama aldol reaction was evaluated using salts $\mathbf{4 a}$ and $\mathbf{4 b} .^{7}$ As a model reaction, 2-naphthaldehyde (5) was reacted with silyl ketene acetal 6 in the presence of catalytic amounts of both TMSCl and chiral sodium borates 4 (Scheme 3). We expected these conditions to generate small quantities of the equivalent of a trimethylsilylium borate salt. With catalyst $\mathbf{4 a}$ the desired aldol product 7 was indeed obtained but racemically. Catalyst $\mathbf{4 b}$ provided aldol product 7 with a small but reproducible 54:46 er. Neither using salt 4 alone nor TMSCl alone led to any product formation under the reaction conditions.

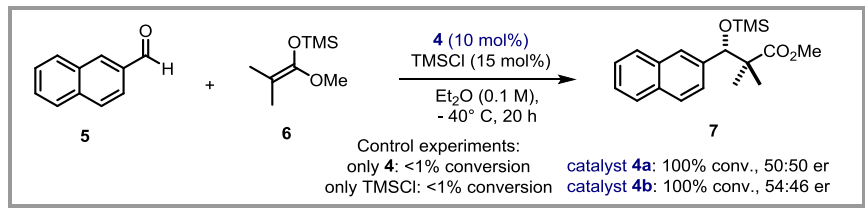

Scheme 3 Application of the $\mathrm{Na}-\mathrm{BAr}^{\mathrm{F}^{*}}$ in Mukaiyama aldol reaction.

In summary, we have developed a short synthetic route to enantiopure weakly coordinating borates from enantiopure BINOL. ${ }^{8}$ The key step of our synthetic route involved a Negishi cross-coupling reaction with electron deficient tetrafluoro-phenyl zinc bromide. The newly designed and synthesized enantiopure borates 4 were evaluated in a Mukaiyama aldol reaction. Clearly, there is a vast potential for weakly coordinating chiral borates in chemistry that can now be explored.

\section{Acknowledgment}

We thank the technicians of our group and the analytical departments of the institute for support of this work. We thank Dr. Sorto and Dr. Alachraf for early contributions. Funding from the Max-Planck-Society and the European Research Council (Advanced Grant CHAOS) is gratefully acknowledged.

\section{References and Notes}

(1) (a) Mahlau, M.; List, B. Angew. Chem. Int. Ed. 2013, 52, 518. Also see: (b) Lacour, J.; Hebbe-Viton, V. Chem. Soc. Rev. 2003, 32, 373. (c) Phipps, R. J.; Hamilton, G. L.; Toste, F. D. Nat. Chem. 2012, 4, 603-614. (d) Brack, K.; Jacobsen, E. N. Angew. Chem. Int. Ed. 2013, 52, 534-561. For early studies: (e) Llewellyn, D. B.; Adamson, D.; Arndtsen, B. A. Org. Lett. 2000, 2, 4165. (f) Carter, C.; Fletcher, S.; Nelson, A. Tetrahedron: Asymmetry 2003, 14, 1995.

(2) (a) Akiyama, T.; Mori, K. Chem. Rev. 2015, 115, 9277. (b) Parmar, D.; Sugiono, E.; Raja, S.; Rueping, M. Chem. Rev. 2014, 114, 9047. (c) Asymmetric Organocatalysis Workbench Edition; List, B.; Maruoka, K., Eds.; Thieme: Stuttgart, 2012 (d) Terada, M. Synthesis 2010, 1929. (e) Kampen, D.; Reisinger, C. M.; List, B. Top Curr. Chem. 2010, 291, 395. (f) Akiyama, T. Chem. Rev. 2007, 107, 5744. Also see: Mao, Z.; Mo, F.; Lin, X. Synlett 2016, 546. (g) Tay, J.-H.; Nagorny, P. Synlett 2016, 551. (h) Lai, Z.; Sun, J. Synlett 2016, 555. (i) Lebée, C.; Blanchard, F.; 
Masson, G. Synlett 2016, 559. (j) Qin, L.; Wang, P.; Zhang, Y.; Ren, Z.; Zhang, X.; Da, C.-S. Synlett 2016, 571. (k) Jiang, F.; Zhang, Y.-C.; Yang, X.; Zhu, Q.-N.; Shi, F. Synlett 2016, 575. (I) Kanomata, K.; Terada, M. Synlett 2016, 581. (m) Zhou, Y.; Liu, X.-W.; Gu, Q.; You, S.-L. Synlett 2016, 586. (n) Monaco, M. R.; Properzi, R.; List, B. Synlett 2016, 591. (o) Hatano, M.; Ishihara, H.; Goto, Y.; Ishihara, K. Synlett 2016, 564. (p) Guo, Y.; Gao, Z.; Meng, X.; Huang, G.; Zhong, H.; Yu, H.; Ding, X.; Tang, H.; Zou, C. Synlett 2017, e-First.

(3) (a) Rueping, M.; Nachtsheim, B. J.; leawsuwan, W.; Atodiresei, I. Angew. Chem. Int. Ed. 2011, 50, 6706. (b) Akiyama, T.; Mori, K., Chem. Rev. 2015, 115, 9277. (c) James, T.; van Gemmeren, M.; List, B. Chem. Rev. 2015, 115, 9388. (d) Coric, I.; List, B. Nature 2012, 483, 315. (e) Gatzenmeier, T.; van Gemmeren, M.; Xie, Y.; Höfler, D.; Leutzsch, M.; List, B. Science 2016, 351, 949. (f) Kaib, P. S. J.; Schreyer, L.; Lee, S.; Properzi, R.; List, B. Angew. Chem. Int. Ed. 2016, 55, 13200. Also see: (g) Kaib, P. S. J.; List, B. Synlett 2016, 27, 156. (h) Lee, S.; Kaib, P. S. J.; List, B. Synlett 2017, e-First.

(4) (a) Großekappenberg , H.; Reißmann, M.; Schmidtmann, M.; Müller, T. Organometallics 2015, 34, 4952. (b) Massey, A. G.; Park, A. J., J. Organomet. Chem. 1964, 2, 245. (c) Hiroshi, K.; Takaaki, S.; Hidetoshi, I.; Masaji, Y., Chem. Lett. 1981, 10, 579. (d) Strauss, S. H., Chem. Rev. 1993, 93, 927. (e) Krossing, I.; Raabe, I., Angew. Chem. Int. Ed. 2004, 43, 2066. (f) Bochmann, M. Coord. Chem. Rev. 2009, 253, 2000. (g) Pollak, D.; Goddard, R.; Pörschke, -R. K. J. Am. Chem. Soc. 2016, $138,9444$.

(5) (a) Barbarich, T. J.; Handy, S. T.; Miller, S. M.; Anderson, O. P.; Grieco, P. A.; Strauss, S. H., Organometallics 1996, 15, 3776. (b) Moss, S.; King, B. T.; de Meijere, A.; Kozhushkov, S. I.; Eaton, P. E.; Michl, J., Org. Lett. 2001, 3, 2375. (c) Anderson, L. L.; Arnold, J.; Bergman, R. G., J. Am. Chem. Soc. 2005, 127, 14542. (d) Chen, M.-C.; Roberts, J. A. S.; Seyam, A. M.; Li, L.; Zuccaccia, C.; Stahl, N. G.; Marks, T. J., Organometallics 2006, 25, 2833. (e)

Roberts, J. A. S.; Chen, M.-C.; Seyam, A. M.; Li, L.; Zuccaccia, C.; Stahl, N. G.; Marks, T. J., J. Am. Chem. Soc. 2007, 129, 12713.

(6) Uozumi, Y.; Suzuki, N.; Ogiwara, A.; Hayashi, T., Tetrahedron 1994, 50, 4293.

(7) García-García, P.; Lay, F.; García-García, P.; Rabalakos, C.; List, B., Angew. Chem. Int. Ed. 2009, 48, 4363.

(8) During the preparation of this manuscript, similar work appeared: Pommerening, P.; Mohr, J.; Friebel, J.; Oestreich, M., Eur. J. Org. Chem. 2017, 2017, 2312.

(9) Synthesis of the $\mathrm{Zn}$-reagent:

A flame-dried $50 \mathrm{~mL}$ Schlenk flask was charged with 1,2,3,5-tetrafluorobenzene $(4.0 \mathrm{mmol}, 1.0$ equiv.) and a magnetic stirring bar. To this Schlenk flask, dry THF (20 $\mathrm{mL}$ ) was added under an argon atmosphere. The mixture was stirred at rt for $5 \mathrm{~min}$ and then cooled to $-78^{\circ} \mathrm{C}$. After $30 \mathrm{~min}$ at $-78{ }^{\circ} \mathrm{C}, n$-BuLi $(2.5 \mathrm{M}$ in hexane, $1.65 \mathrm{~mL}, 4.1$ $\mathrm{mmol}, 1.02$ equiv.) was slowly added through the cold sidewall of the flask under an argon atmosphere (Note: direct addition of $n$-BuLi to the cold mixture could lead to an explosive reaction). The reaction mixture was stirred at -78 ${ }^{\circ} \mathrm{C}$ for $1 \mathrm{~h}$ and freshly dried $\mathrm{ZnBr}_{2}$ (1.0 M solution in THF, $4.2 \mathrm{~mL}, 4.2 \mathrm{mmol}, 1.05$ equiv.) was slowly added to the reaction mixture and stirring was continued for $20 \mathrm{~min}$. The dry-ice bath was removed and the reaction mixture was allowed to warm up to rt. After $20 \mathrm{~min}$ at rt, $\sim 15 \mathrm{~mL}$ of THF was removed under reduced pressure (Schlenk technique). This Zn-reagent was directly used for the next step.

(10) General Procedure for Negishi Cross-Coupling: A flame-dried $25 \mathrm{~mL}$ Schlenk flask was charged with compound (S)-1 (1.0 mmol, 1.0 equiv.) and a magnetic stirring bar. To this flask, the freshly prepared Zn-reagent (4.0 mmol, 4.0 equiv.) was transferred under an argon atmosphere. The mixture was degassed (three times) and $\mathrm{Pd}\left(\mathrm{PPh}_{3}\right)_{4}(10 \mathrm{~mol} \%, 0.1 \mathrm{mmol}, 0.1$ equiv.) was added. The reaction mixture was then heated to $100{ }^{\circ} \mathrm{C}$ for $24 \mathrm{~h}$. Then the reaction mixture was cooled to $\mathrm{rt}$ and treated with saturated aq. $\mathrm{NH}_{4} \mathrm{Cl}$. The crude reaction mixture was extracted with $\mathrm{CH}_{2} \mathrm{Cl}_{2}(3 \times 10 \mathrm{~mL})$, dried over $\mathrm{Na}_{2} \mathrm{SO}_{4}$, and concentrated under reduced pressure. Purification was performed by $\mathrm{SiO}_{2}$ column chromatography using $10 \%$ $\mathrm{CH}_{2} \mathrm{Cl}_{2} / i$-Hexanes.

(S)-2a: Prepared according to the general procedure as colorless solid in $72 \%$ yield. ${ }^{1} \mathrm{H}$ NMR $\left(500 \mathrm{MHz}, \mathrm{CD}_{2} \mathrm{Cl}_{2}\right): \delta$ $8.11(\mathrm{~d}, J=8.5 \mathrm{~Hz}, 1 \mathrm{H}), 8.03(\mathrm{~d}, J=8.3 \mathrm{~Hz}, 1 \mathrm{H}), 7.85(\mathrm{~d}, J$ $=8.2 \mathrm{~Hz}, 2 \mathrm{H}), 7.60-7.54(\mathrm{~m}, 1 \mathrm{H}), 7.52(\mathrm{~d}, J=8.5 \mathrm{~Hz}, 1 \mathrm{H})$, 7.50-7.45 (m, 1H), 7.44-7.38 (m, 2H), 7.36-7.29 (m, 1H), 7.29-7.21 (m, 3H), 6.88-6.77 (m, 1H).

(S)-2b: Prepared according to the general procedure as colorless solid in $81 \%$ yield. Compound $(S)$-2b exists as a $1: 1$ mixture of rotamers. ${ }^{1} \mathbf{H}$ NMR $\left(500 \mathrm{MHz}, \mathrm{CD}_{2} \mathrm{Cl}_{2}\right): \delta 8.09$ $(\mathrm{d}, J=8.5 \mathrm{~Hz}, 2 \mathrm{H}), 8.02(\mathrm{~d}, J=8.2, \mathrm{~Hz}, 2 \mathrm{H}), 7.88-7.80(\mathrm{~m}$, $4 \mathrm{H}), 7.60-7.53(\mathrm{~m}, 2 \mathrm{H}), 7.53-7.37(\mathrm{~m}, 8 \mathrm{H}), 7.34-7.28(\mathrm{~m}$, $2 \mathrm{H}), 7.28-7.18(\mathrm{~m}, 6 \mathrm{H}), 6.67-6.58(\mathrm{~m}, 1 \mathrm{H}), 6.52-6.39(\mathrm{~m}$, $1 \mathrm{H})$.

(11) General Procedure for Synthesis of 4:

A flame-dried $25 \mathrm{~mL}$ Schlenk flask was charged with compound (S)-2a (1.0 mmol, 1.0 equiv.) and a magnetic stirring bar. To this flask dry $\mathrm{Et}_{2} \mathrm{O}(5 \mathrm{~mL})$ was added under an argon atmosphere. The mixture was stirred at rt for 5 min to dissolve the substrate and was then cooled to -78 ${ }^{\circ} \mathrm{C}$. After $30 \mathrm{~min}$ at $-78{ }^{\circ} \mathrm{C}, n$-BuLi $(2.5 \mathrm{M}$ in hexane, 0.42 $\mathrm{mL}, 1.05 \mathrm{mmol}, 1.05$ equiv.) was slowly added through the cold side-wall of the flask. The reaction mixture was stirred at $-78{ }^{\circ} \mathrm{C}$ for $4 \mathrm{~h}$. After $4 \mathrm{~h}, \mathrm{BCl}_{3}(1.0 \mathrm{M}$ solution in heptane, $0.2 \mathrm{~mL}, 0.2 \mathrm{mmol}, 0.2$ equiv.) was slowly added to the reaction mixture and warmed up to it over $4 \mathrm{~h}$ and the stirring was continued for overnight. Then the reaction mixture was cooled and subsequently quenched with saturated $\mathrm{NaCl}$ (aq.). The crude reaction mixture was extracted with $\mathrm{CH}_{2} \mathrm{Cl}_{2}(3 \times 10 \mathrm{~mL})$, dried over $\mathrm{Na}_{2} \mathrm{SO}_{4}$, and concentrated under reduced pressure. Purification was performed by $\mathrm{SiO}_{2}$ column chromatography using $10 \%$ $\mathrm{MeOH} / \mathrm{CH}_{2} \mathrm{Cl}_{2}$. The purified product was dissolved in $\mathrm{CH}_{2} \mathrm{Cl}_{2}$ and $10 \mathrm{~mL}$ saturated $\mathrm{NaCl}$ (aq.) solution was added and the reaction mixture was vigorously stirred for $20 \mathrm{~min}$ at rt. It was then extracted with $\mathrm{CH}_{2} \mathrm{Cl}_{2}(3 \times 10 \mathrm{~mL})$, dried over $\mathrm{Na}_{2} \mathrm{SO}_{4}$, and concentrated under reduced pressure.

(S)-4a: Prepared according to the general procedure as white solid in $52 \%$ yield. ${ }^{11} \mathrm{~B}$ NMR $\left(160 \mathrm{MHz}, \mathrm{CD}_{2} \mathrm{Cl}_{2}\right)$ : $\delta-$ 17.12. HRMS $m / z$ (ESI): calcd. for $\mathrm{C}_{104} \mathrm{H}_{52} \mathrm{BF}_{16}$ [M] 1615.39205; found 1615.39121 .

(S)-4b: Prepared according to the general procedure as white solid in $41 \%$ yield. ${ }^{11} \mathrm{~B}$ NMR $\left(160 \mathrm{MHz}, \mathrm{CD}_{2} \mathrm{Cl}_{2}\right)$ : $\delta-$ 17.22. HRMS $\mathrm{m} / \mathrm{z}$ (ESI): calcd. for $\mathrm{C}_{104} \mathrm{H}_{52} \mathrm{BF}_{16}[\mathrm{M}]^{-}$: 1615.39205, found 1615.39121 .

(12) General Procedure for Mukaiyama Aldol Reaction:

An oven-dried $2 \mathrm{~mL} \mathrm{GC}$ vial was charged with catalyst 4 (4.1 mg, $0.0025 \mathrm{mmol}, 0.1$ equiv.) and a magnetic stirring bar. To this vial, $\mathrm{Et}_{2} \mathrm{O}(0.25 \mathrm{~mL})$ was added followed by TMSCl $(0.48 \mu \mathrm{L}, 0.0038 \mathrm{mmol}, 0.15$ equiv.) under an argon atmosphere. The mixture was then stirred at $\mathrm{rt}$ for $5 \mathrm{~min}$ and the mixture then cooled to $-78{ }^{\circ} \mathrm{C}$. To the mixture, aldehyde 5 (3.9 mg, $0.025 \mathrm{mmol}, 1.0$ equiv.) was added followed by silyl ketene acetal $6(6.4 \mu \mathrm{L}, 0.031 \mathrm{mmol}, 1.25$ equiv.). The reaction vial was warmed to $-40{ }^{\circ} \mathrm{C}$. After 20 $\mathrm{h}$, the reaction was quenched with saturated $\mathrm{Na}_{2} \mathrm{CO}_{3}$ (aq.) solution and the crude mixture was directly purified without further work-up on $\mathrm{SiO}_{2}$ preparative TLC using $5 \%$ EtOAc/ $i$ Hexanes $(v / v)$ as eluent. (Note: Two sets of control 
experiments were performed where only catalytic amount of either $\mathbf{4 a}$ or TMSCl was used. No aldol product 7 was observed). 